\title{
'Working from home is better than going out to the factories' (?): Spatial Embeddedness, Agency and Labour-Market Decisions of Women in the City of Delhi
}

Sonal Sharma and Eesha Kunduri

\section{(2) OpenEdition}

\section{Journals}

Electronic version

URL: http://journals.openedition.org/samaj/3977

DOI: 10.4000/samaj.3977

ISSN: 1960-6060

Publisher

Association pour la recherche sur l'Asie du Sud (ARAS)

\section{Electronic reference}

Sonal Sharma and Eesha Kunduri, « 'Working from home is better than going out to the factories' (?): Spatial Embeddedness, Agency and Labour-Market Decisions of Women in the City of Delhi », South Asia Multidisciplinary Academic Journal [Online], Free-Standing Articles, Online since 07 September 2015, connection on 30 April 2019. URL : http://journals.openedition.org/samaj/3977 ; DOI : 10.4000/ samaj.3977

This text was automatically generated on 30 April 2019

\section{(c) (i) () $\Theta$}

This work is licensed under a Creative Commons Attribution-NonCommercial-NoDerivatives 4.0 International License. 


\title{
'Working from home is better than going out to the factories' (?): Spatial Embeddedness, Agency and Labour-Market Decisions of Women in the City of Delhi
}

\author{
Sonal Sharma and Eesha Kunduri
}

\section{Introduction}

1 This paper ${ }^{1}$ is an attempt to understand the dynamics of labour market decisions of women living in and around two industrial estates in the city of Delhi. By looking at the labour market decisions of women in three different sites and forms of work, we examine the role of location of the work-at one's own home (as home based workers), someone else's home (in the form of paid domestic work) and conventional workplaces like factories (as shop-floor workers and as cleaners)-in shaping these different work choices for women in the informal sector. Our inquiry is fundamentally directed towards understanding what Naila Kabeer (2000: 330) notes about women's decisions to enter paid employment, which is about 'whether to take up paid work as well as when and what kind of work.' A vast body of literature argues that women's labour market decisions are much more than just 'economic', they are socially, culturally and spatially embedded (Kabeer 2000, Hanson \& Pratt 1995). Herod (2003) argues that workers are 'spatial as well as historical social agents,' and emphasises the need to engage theoretically with the 'spatial' for a nuanced understanding of working class lives. Women, he notes, are spatially embedded more in home and in the private sphere, which explains their low presence in formal workplaces. The concept of spatial embeddedness highlights women's primary location as gendered subjects within the space of home, unlike men whose sense of masculinities is very deeply entrenched in their movement in what is called "public 
sphere.' To us, the various gendered forms of work organisation have, what Doreen Massey (1994: 168) calls, 'spatial form and content.'

This paper attempts to see 'spatial content' in the labour market decisions of women and tries to examine meaning and significance of that to better understand and situate the choices made by the women workers. Drawing upon work/life history interviews, we explore the spatiality and temporality of women's decisions to navigate particular forms of paid work, by contextually situating the varying expressions of choice across the three sites of work. We argue that women's efforts to choose one kind of work arrangement over another are embedded in the power and control that certain spaces of work entail. We further argue that women workers actively seek to reshape and redefine these spaces, through conscious negotiations in everyday practice as well as discourse.

The paper is primarily based on narratives of 30 women workers in worker settlements around two industrial estates in Delhi, and on field observations derived from extensive visits to the settlements over a period of one year, from May 2013 to June 2014. The key findings of the paper were further confirmed on a revisit to the field in April 2015. ${ }^{2}$

\section{Methodology}

4 The inspiration to undertake a comparative analysis of labour market decisions of women across three sites of work-factory work, home-based work and domestic work arose in the summer of 2013, during the course of fieldwork for a larger research project on migration and industrial work in the city of Delhi. As we explored worker settlements around two industrial estates in Delhi-Patparganj in East Delhi, and Wazirpur in NorthWest Delhi, ${ }^{3}$ we initially encountered difficulties in locating and speaking with women workers, who worked in the industrial estates. Amidst this difficulty, however, we were also struck by the presence of a diverse set of industrial outworkers (homeworkers ${ }^{4}$ ), engaging in various kinds of work-sewing on the sides of jeans, putting threads into bookmarks, taping of speaker components, to name a few. Our initial interactions with these home-based workers raised a set of questions. In settlements in close geographical proximity to an industrial estate, what factors drive the decision of women to undertake home-based work compared to work in the factories? What differences exist between these two groups of workers in terms of their ideas and perceptions of work?

But soon enough, we realised that a comparison across these two groups of workers had limitations, as in both the cases, the settlements where workers from the industrial estates resided were also surrounded by middle-class housing societies/residential neighbourhoods. For the women residing in these settlements, this proximity rendered paid domestic work a viable livelihood option. The workers from the Patparganj industrial estate were primarily living in two urban villages, namely Bhoapur and Ghazipur located right next to the estate, and in two slum settlements (colloquially referred to as bastis)-in Madhu Vihar (Indira Camp) and Khichripur (Figure 1). The middle class residential neighbourhoods lie to the west of Indira Camp, and can be visually identified as well-laid out settlements with green spaces, when contrasted with the density that characterises the worker settlements. Similarly, in case of Wazirpur, the settlements Azadpur, Wazirpur basti and Lal Bagh were the prime localities wherein workers from the estate resided (Figure 2). To the north and south of the estate are middle-class residential neighbourhoods. 
Figure 1:

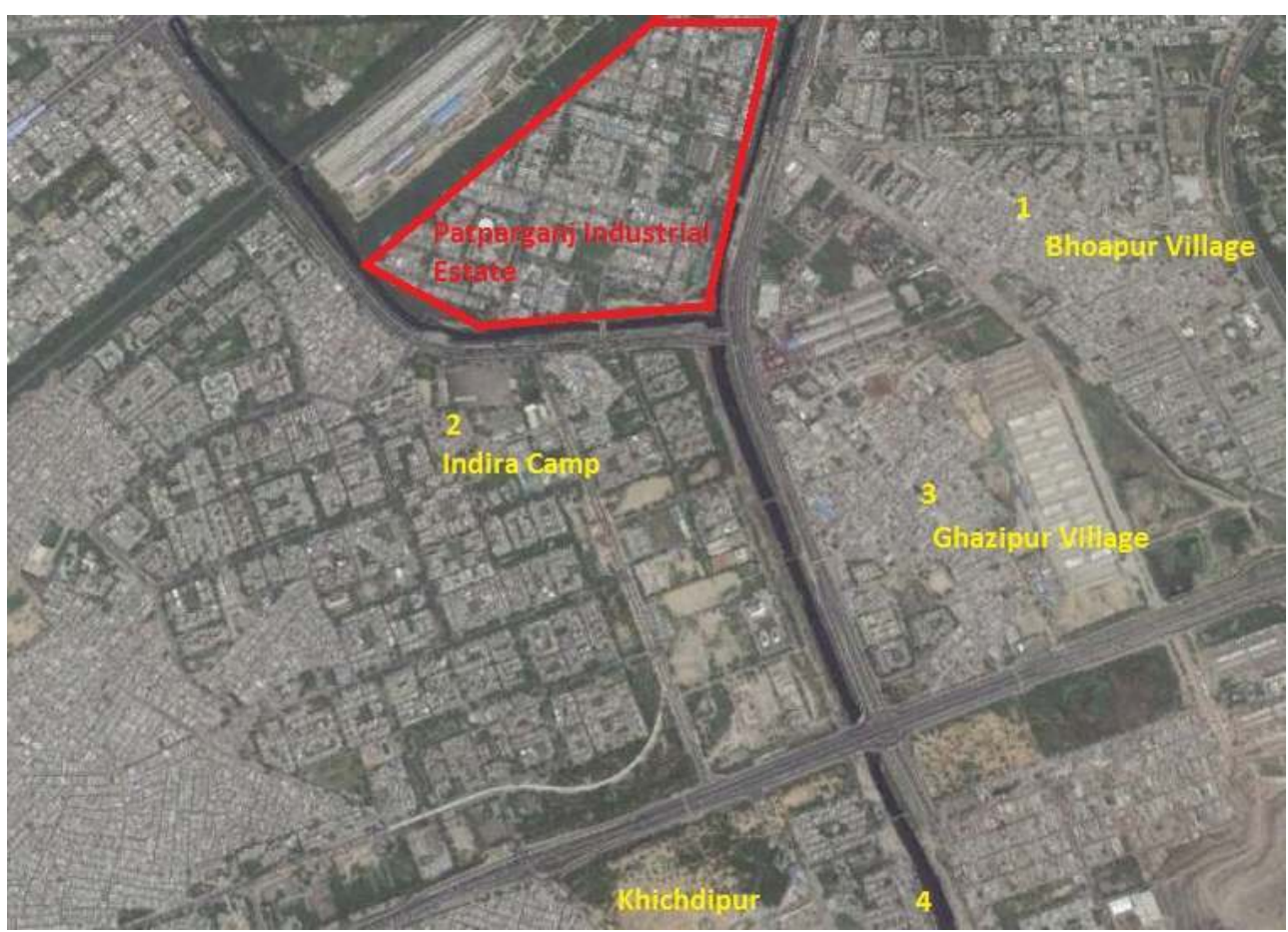

PATPARgANJ INDUSTRIAL ESTATE AND THE WORKERS' LOCALITIES

(C) Google Earth)

Figure 2:

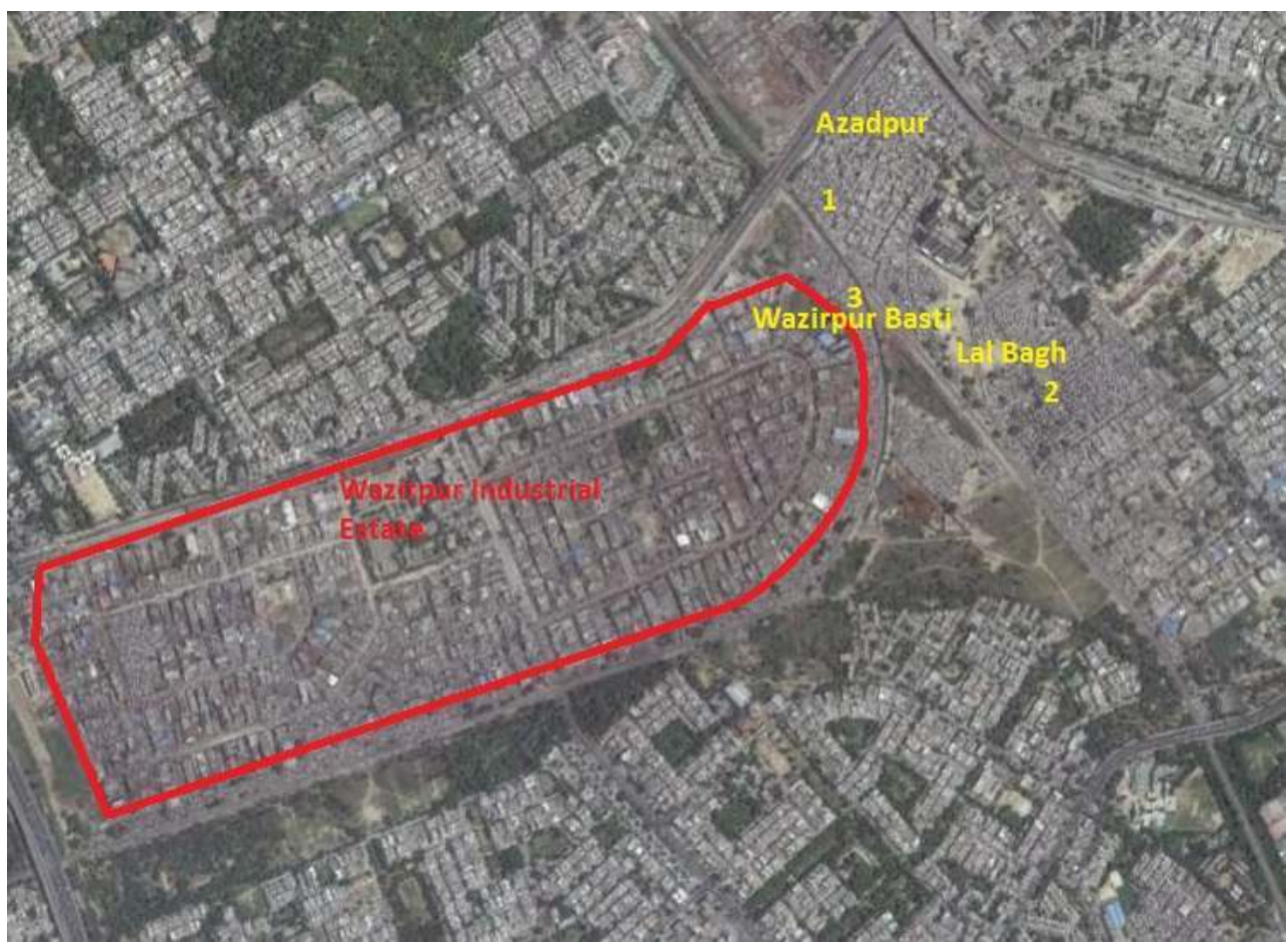

WAZIRPUR INDUSTRIAL ESTATE AND THE WORKERS' LOCALITIES

(C GOOgLE EARTH) 
6 The idea of this kind of comparative analysis appealed to us also because of the spatial features the three arrangements had, which seemed promising to understand the dynamics of women's choices pertaining to work. In the case of domestic workers who work in the 'private space' of someone else's home, the employers' home is the workers' workplace, while in home-based work, workers' own home becomes a site of work for a certain duration. On the other hand, the factory is a site of work that features in conventional ideas of a workplace. ${ }^{5}$ The three sites of work could provide highly relevant insights to explore the spatial context of labour market decisions of women workers. Further, as we realised through the course of fieldwork, the categories of factory worker, domestic worker and home-based worker are not water-tight. Eight of the thirty women interviewed had worked in more than one of the three worksites, and one worker had worked across all three worksites at different time periods in her life, which reiterated to our minds the need to undertake such a comparative analysis. Of the remaining workers in the sample, ten women worked as factory workers, nine as home-based workers and two as domestic workers. A crucial aspect of the comparative analysis of worksites in this paper, therefore, draws upon the lived experiences of those who have worked across sites, in addition to the notions articulated by those who have worked only at one.

7 All the workers interviewed are migrants to the city, mostly from the states of Uttar Pradesh and Bihar in North India. None of the women have migrated independently for work, and most of them relocated to Delhi with their husbands, and started working only after a few years in the city. Except three women in their fifties who are widowed, all the workers in the sample are married, though their ages range between twenty one years to fifty years. Approximately, most workers earn between rupees 4000-4500 a month, though a few of them reported earnings below rupees 2500 a month.

\section{Gender and work through the lens of space: An overview}

8 Spaces are understood as geographies in relation to particular social interactions and relations, which are not a priori; rather they come into existence as they are lived and perceived by social subjects (Massey 1994). When social relations, practices and perceptions are seen in the particular kinds of geographies they take place in, we essentially engage with the socio-spatiality of those geographies. Feelings and emotions of individuals become instrumental to understand spaces from the subjects' point of view (Ranade 2007, Low 2006, Abraham 2010). People play an important role in constructing spaces but they do not produce spaces through their actions thoughtlessly. People try to make sense of spaces when they enter them, literally, and act in response to the particular setting through their actions based on their perception of it (Richardson 1982). The process of making sense of various social and material settings is not independent of subjects' own social position. For example, women's fear of unknown public spaces can be located in the hegemonic masculinist understanding that reminds them where they ought to be safe, that is the home; which is also 'embodied' by women themselves (Bondi \& Davidson 2005, Phadke et al. 2011, Baydar 2012).

Whether women will travel long distances or short distances for work, or not travel and become home based workers, sheds light on the spatial aspect of these decisions. These choices of work, in addition to showing patterns of economic choices, also show spatial 
choices, such as the choice between home and a formal workplace, and between a workplace further away when compared to a factory next door. Due to their spatial embeddedness in home, women tend to travel shorter distances for work as it allows them to undertake both domestic responsibilities and wage labour, which also implies that they are often dependent on what is locally available (Hanson \& Pratt 1995). For example, it has been argued that the reason behind preference of part-time domestic work by working class women is located in the geographical proximity of the two kinds of localities (low-income housing settlements located next to middle and upper middle class residential neighbourhoods) that allows women to undertake paid work, and look after their household chores in between (Neetha 2004, Anand \& Tiwari 2006). However, the geographic explanation, on its own, is not sufficient enough to explain why paid domestic work is largely feminised. It is feminised also on account of the gendered nature of work it entails, its social valuation as 'devalued work,' and its informal character, defined by the lack of standard employment contracts and little or no job security (Neetha \& Palriwala 2010, Raghuram 2001). Estimates of the National Sample Survey Organisation (NSSO) for the last one decade show that women make up no less than two-thirds of the total number of domestic workers in the country: the 2004-05 estimates, for instance, reveal that out of 4.2 million domestic workers in the country, 3 million are women in urban $\operatorname{areas}^{6}$ (Kaur 2006, Neetha 2009). According to a report by the National Commission for Enterprises in the Unorganised Sector, an overwhelming $54 \%$ of regular women workers in the unorganised sector are concentrated in work in private households, primarily in domestic services (NCEUS 2007).

In addition to women workers in a 'feminised' occupation such as domestic work, the paper involves an appraisal of work choices of women in two variants of industrial work organisation which reproduce gender inequality in the world of work: gender-based occupational segregation of industrial tasks, and home-based work (also known as industrial outwork). These situate women in vulnerable and precarious conditions of work, and the correlations between informal work and women's work have been observed to be particularly strong-women are concentrated as piece-rated workers in factories, as home-based workers at the bottom of subcontracting chains, as low-paid wage labour in sweatshop production-employment scenarios that consciously play into women's social position relative to men, and create further vulnerabilties (Ghosh 2004). While at one level it has been mooted that women have become more 'visible' through their integration into paid employment, this visibility and its impact on women's overall social standing and mobility is questionable (Arizpe \& Aranda 1986). Household responsibilities such as cooking and child-rearing are borne by women primarily, and despite their inclusion in the workforce, women continue to hold the status of secondary earners. However, a growing body of literature has argued about the emancipatory potential of wage work for women, however precarious and vulnerable, and on the need to situate women's agency and decision-making with regard to their own employment within the framework of these debates. In this strand of literature, scholars have argued in favour of listening to the 'voices' of women and understanding how they themselves make sense of their circumstances (Kabeer 2000, Fernandez-Kelly \& Wolf 2001).

The work of Kabeer for instance, contributes to a nuanced assessment of the sociocultural context of women's work under globalisation. In her work on Bangladeshi workers in two distinct geographical/cultural contexts of the global garment industryfactory workers in Dhaka and home-based workers in London, Kabeer (2000) looks at the 
intertwining nature of women's decisions to work with the cultural values and notions of femininities. She argues that culture does not influence these decisions as an external force but is very much part of the desire of the workers. To be able to account for the exercise of agency by women workers then, it is important to look at them as neither as 'rational fools' nor as 'cultural dopes' (Kabeer 2000). A pursuit of 'agency' in human actions essentially involves understanding not just the actions and outcomes that are deemed to be symbolic of agency, but also how the human subjects make sense of these actions. The question of what kind of actions symbolise agency and what do not is a contested one (Mahmood 2001, Abu-Lughod 2002). A popular and often mistaken understanding of agency is that of agency as resistance. Ahearn (2001) rightly points out that resistance to structures of power represents only one expression of agency, that is 'oppositional agency,' and that agency can have many other expressions. In the context of Muslim women's experiences of gender relations in Egypt, Mahmood (2001: 210) unsettles the dominant understanding of agency, one that draws upon white, Euro-American women's experiences and embodies the liberal notion of 'freedom.' Instead, she proposes an alternative lexicon to understand agency 'as a capacity for action that specific relations of subordination create and enable.' The idea behind such a provocative articulation is to destabilise the essentialised category of women and gender oppression. In this theorisation, agency is a continuum between conformity and overt resistance, and 'resistance' is a form in which it may manifest. Thus, an act which appears to be that of 'conformity' is not necessarily devoid of agency.

Individuals can manoeuvre structures that constrain their freedom to exercise certain types of choice. Social structures do not only shape spaces but spaces themselves are seen as structures that can constrain individuals' (in this case women's) choices (Phadke et al. 2011, Lefebvre \& Levich 1987). Spaces play an important role in enabling/disabling women to do paid work (Hanson \& Pratt 1995) and thus they are more than just the 'background' when women workers express their decisions to work. The paper, therefore, attempts to explore the 'spatial embeddedness' (Herod: 2003) of the labour market decisions of women, and how they negotiate the spatial constraints, real or perceived. Though the primary focus of this paper is to look at how women workers make sense of their work, it also situates their efforts of 'meaning-making' in relation to 'the actual conditions that engulf them and their families' (Fernandez-Kelly \& Wolf 2001: 1245).

\section{Choices reflecting preference of certain work-sites over others}

13 Spaces are relational (Gottfried 2013), and come into existence through social relations and interactions. Spaces do not exist as a priori to social subjects; rather they are shaped by them and feed back into the social relations that they are shaped by (Massey 1994). Social relations are governed by norms, and norms play an instrumental role in defining the boundaries of spaces (Chakrabarty 1993, Kaviraj 1997, Abraham 2010). Social relations are so intrinsic to spaces that changes in the relations can change meaning and experience of spaces. Gottfried (2013), for instance, argues that the employment of domestic help in a middle class household, turns home, a site of social reproduction, into a site for production, on account of the paid-work undertaken by the domestic help in the home. According to her, such changes redefine relations of power which further redefine the space of home. In our study, the narratives of women workers have reference to 
spaces and their relational aspect. The narratives indicate that choices of certain occupations over the others are also choices about certain kinds of work and power relations. Workers can choose to work in a factory a few kilometres away rather than in a household in a nearby middle class neighbourhood, primarily because of the two different kinds of work relations the two spaces entail. As the narratives of women workers in this section demonstrate, often choices of work are also about certain types of work relations, which in turn are rooted in social hierarchies of class and gender.

Let us consider, for instance, the case of Lakshmi, ${ }^{7}$ who migrated to Delhi twenty five years ago along with her husband, and has been working in the Patparganj industrial estate for the past five years. She is in her late thirties and hails from the state of Uttar Pradesh. At the time we interviewed her, she was working in an incense factory in the estate, and her job involved packing of camphor. Since her husband's work as a beldar (construction worker) in the city was contingent on the availability of work, which was not very frequent, she began working in the estate so as to have a regular flow of income to be able to provide for the needs of her four kids. 'If there wasn't any problem, then why would I work? Why would I go out,' she argues, explaining the financial pressures that drive her employment into factory work. When we asked her if she had considered working as a part-time domestic worker in the nearby housing societies, given that she could earn a similar income, and save on travel time, she responded that she preferred her current work in the factory, as it required being at one place for eight hours, and she could come back home without her clothes getting 'dirty.' Her decision to not work as a domestic worker is also based on what she has heard from other domestic workers living in the basti about the nature of tasks and workload-that the work in employing households is never ending, and that the employers ask you to undertake additional tasks even when you are just about to leave for the next household for work. In the same vein, however, she notes that if the need arises, she can undertake 'cleaning' work in a factory but will not work as a domestic worker.

Domestic work is notorious for its ill-defined nature of tasks (Neetha \& Palriwala 2010) because it is not undertaken at formal workplaces or conventional spaces identified with work. It is argued that the lack of well-defined tasks is rooted in the nature of home-a space of personalised and emotional care; and it is due to this reason that employers are also not able to give clear-cut instructions to workers (Morus 2008). The spatial angle that entails in 'home as a workspace' is vividly brought forth in the accounts of workers in our study who work as part-time factory cleaners in the Patparganj industrial estate, and have previously worked in households as domestic helps. Their comparative view, drawing upon their own lived experiences of work in these two sectors, brings forth a clear demarcation between the workspace of the factory and the home, and an outright preference for 'factory work,' even though the tasks that they perform in the factories where they work are essentially in the nature of cleaning services. The relatively welldefined nature of the tasks in the factory, when compared to the home and how it factors into the decision to choose between these two sites of work is brought forth in the following interaction held with a group of women working as part-time factory sweepers in the Patparganj industrial estate:

Kamala: What needs to be understood is that if a woman works in households and for some reason she stops working there, thereafter she starts working in a factory in Patparganj, then, after that, she would not like to go back to domestic work because in the households, they make us do extra work and pay less. 
Rani: They pay less, and then, what also happens is that if we are cleaning the dishes and you [the employer] are cooking something in a wok then you [the employer] will think of emptying that wok quickly and giving it for washing, you know? 'I am eating and this plate will require washing after I finish'-they say like this. They keep giving us work even when we are leaving.

Towards a later part of the discussion, as Kamala narrates how she switched from being a domestic worker to a factory cleaner, a very clear sense of the well-defined nature of work in the latter, and her preference for one over the other emerges. She explains that five years ago, she quit working in the nearby housing societies, as she fell extremely sick due to the workload during peak winters, since the multitude of tasks her work entailed, such as mopping the floor, cleaning dishes, washing clothes across the houses where she worked, required working with cold water. For a long while, she explains, that despite the sickness she would go to work every day popping a pill, until one day she no longer could sustain it. There is both anger and hurt in her voice as she remarks that none of her employers told her to take leave, despite her health.

I left [domestic] work because of my illness. No madam ever said that 'Kamala, you are unwell so go back home, take leave, or do not come to work.' I was so sick that I had to take a rickshaw to go and tell my employer that I will not come to work... After that, I started working in Patparganj. When I joined work in Patparganj, I was asked to do two tasks. It was a big factory but I never did any extra work, above and beyond the two tasks I was designated to do. So, I did not like this work [domestic work] but I liked this work [factory work]. In domestic work, I was frequently asked to do tasks last minute, just when I was about to leave.

Similary, Rakhi, a migrant from Uttar Pradesh, who is in in her forties, remarks on the illdefined nature of the tasks in domestic work, 'It usually happens in the households [which employ us] that in addition to the work we are hired for; we are made to do extra work.' At the time we interviewed her, Rakhi was looking for work, as she was recently asked to resign from her work as a housekeeping incharge at an office in Ghaziabad, almost twenty kilometers away from her place of residence. Men were being hired instead for all the cleaning services, according to her, though it was not entirely clear if this was the primary reason for her dismissal. What was significant to note was the fact that she was looking for a similar work profile of housekeeping in an office or a factory, but was not willing to undertake domestic work. Rakhi's decision to not work as a domestic worker, and her understanding and perception of it, based on what she has heard from other women in the settlement, is however, in sharp contrast to her own experience of working as a domestic worker in South Delhi many years ago, which she reminisces with fondness as a thing of the past. Her experience of domestic work was good in 'those days' as she resided in a servant quarter, was paid relatively well, and all her other needs were provided for. She compares that to the scenario now in the following words:

Bungalows and big houses are good to work in, as usually servant quarters are attached to them. You are provided with a good accommodation and other facilities, what does one get [by working for a household] in a housing society? Domestic work now has changed a lot since the time I used to work as a domestic worker and live in a servant quarter.

The above set of testimonies suggest that often more or less similar kind of tasks (cleaning/ sweeping/) in a factory or an office is preferred over paid domestic work in households due to the relatively well-defined nature of the tasks in the former. We suggest that these differences that are projected as differences in two kinds of work by our informants are inherent in the nature of spaces they take place in. While the work in 
factories may not be formalised and well-defined in the ideal sense, but it remains better in comparison to domestic work, which takes place in the private space of someone else's home. The relatively well-defined nature of work can be attributed to years of development of a work culture, which includes not only what government and firms promote, but also what workers develop themselves and share through informal networks and through it, become part of the work relations. Domestic work, on the other hand, lacks this kind of work culture for obvious historical and socio-cultural reasons, which tend to devalue any work in 'home.' The informal and unregulated nature of domestic work further contributes to sustaining the lack of workplace rights and the limited bargaining power of workers. The location of work in isolated workplaces reduces the chances of building solidarities at work, and poses challenges to collectivisation. (Neetha 2008, Devika et al. 2011).

\section{Choices reflecting negotiations of honour and safety}

In contrast to the narratives presented in the preceding section, is a testimony by Seema, a Muslim woman hailing from Uttar Pradesh, who expresses a clear preference for domestic work over factory work. Like Rakhi, Seema has always worked and lived in a servant quarter in South Delhi, and liked the work arrangement as it provided for all her needs. However, when she moved to Mukundpur, a settlement in North-West Delhi, and began working in the packing department of a steel factory, she could not stand the sexualised nature of the factory space, and quit soon after. The following excerpt of a conversation with her brings this forth:

Eesha: You have worked as a domestic worker for years and have also worked in factories, so how has your experience been of working in two different kinds of workplaces?

Seema: I liked working as domestic worker more. It is because if you work in a factory, they [men] touch you in inappropriate places. It happens a lot... I could not work in Wazirpur for very long.

She also narrates to us a recent account of working in a tobacco factory, wherein she was fired when she complained and voiced her protest against abusive language written on the factory doors and walls.

A few days ago, I worked in a tobacco factory. I could not work there for long. Something was written in really foul language on the doors. I raised my voice about it and told the contractor: See, thekedar ji (contractor sir) young men and women work here and these dirty things are written here. Why is it so? After that I was fired.

Ever since they got drawn into manufacturing jobs, working class women have struggled with the sexualisation of their presence in factory spaces (Elson \& Pearson 1981). The sexual harassment of working women, as has been extensively argued, serves to reinforce and reproduce gendered hierarchies and inequalities at the workplace (Siddiqi 2003). We suggest that the above accounts by Seema highlight how the everyday material and symbolic representations of power/dominance by male co-workers and contractors manifest in creating a sexualised atmosphere on the shop-floor, which gets legitimated and reproduced when Seema is fired for raising her voice against it. Similar to Seema, another domestic worker expressed her disdain for factory work, citing cases of quid-proquo sexual harassment of women workers, and observed that such vulnerabilities inherently define factory work and render women workers helpless (majboor). 

we note that women consciously factor in their relative position vis-à-vis male coworkers in their decisions to undertake certain kinds of work. These power relations are embedded in the gender inequality that plays out in shaping female subjectivity in context of workspace. Often, the shop-floor can be extremely masculine due to prominence of the number of male workers and this produces that space as one in which, as Bondi and Davidson (2005: 21) note, women find themselves as the subjects of gaze. They further state that it is this fear of gaze which, for women, "creates and strengthens the notion that [the] space is not our own.' For women to move out of their homes and work in conventional workplaces, which also happen to be conventionally male dominated, requires them to keep aside a 'masculinist imagination' which reinforces their entrapment in their own homes (Bondi \& Davidson 2005). Geeta and Sapna explain their choice to work from home while also highlighting the threatening potential of the 'male gaze' in factories:

Geeta: In factory, male co-workers usually look at female co-workers with an evil sexualised gaze.

Sapna: and there, we will work under someone else. Here [when we work from home], we work under ourselves; even if we commit some mistake in work, we can rectify it and send it [later].

The duo's explanation above makes it apparent that their choice of not working in factory is also about avoiding certain kinds of power relations between male and female workers that shape factory spaces. It goes on to reveal how the sexualised nature of the shop-floor renders working outside their homes a less desirable option for women. Further, what is interesting to note is Sapna's remark on not having to work under anyone else in their own homes, which confers upon them a certain degree of control over the work they do. As Geeta points out towards a later part of the discussion, on the advantages of homebased work vis-à-vis work in a factory: 'It is a matter of our own choice. We work if we feel like, if we do not feel like then we can just sleep.' Such anecdotes on not choosing factory work for reasons of autonomy and avoidance of power of formal workplaces strongly relate to what Harris-White and Prosperi (2014) call 'micro-political-economy of gains.' The authors argue that the strategies through which the unorganised workforce tries to reduce its vulnerabilities and achieves improvements in its working conditions are critical to look at. For instance, the move to self-employment from wage labour can be a move for a 'gain in work quality [...] rather than as a form of production or trade generating an opportunity to accumulate' (Harris-White \& Prosperi 2014: 41). We argue that the perspectives discussed above give us a context in which the workers' choices are shaped by their assessment of the gendered vulnerabilities a shop-floor, as a specific type of workplace, represents. In referring to the vulnerabilities pointed out by women workers as 'gendered,' we draw upon Acker (1990: 146), who writes that, 'to say that an organization, or any other analytic unit, is gendered means that advantage and disadvantage, exploitation and control, action and emotion, meaning and identity, are patterned through and in terms of a distinction between male and female, masculine and feminine.' The gendered nature of organisational structures and processes, according to her, is rooted in the commonplace image of the quintessential male worker, presumed to be devoid of emotions, sexuality and familial ties, which significantly reproduces gender differences and hierarchies at workplaces. By choosing to work as home-based workers, and 'under their own control,' we argue that Geeta and Sapna highlight their agency to choose a site of work which holds for them relatively better conditions of work. It is

South Asia Multidisciplinary Academic Journal , Free-Standing Articles 
worth noting that the two do not work merely as home-based workers; but also sublet work to other women in the locality, after themselves obtaining the materials from the nearby workshops. Thus, in their case, the choice is not only about avoiding the subordinate position inherent in certain workplaces, but also about gaining power, however small, by choosing work-relations made possible by other types of worksites.

It becomes crucial to point out here that the work options for Sapna and Geeta are significantly constrained by the fact their children are extremely young, which makes it even more difficult for them to undertake full-time factory work. This confirms what Kabeer (2000:330) observes that for women, labour supply decisions involve taking into account the domestic labour (which substantially includes childcare responsibilities) that they are expected to do, which has 'prior claims on their time.' Prior to her current work, three years ago Geeta was working as an interlock machine operator in a garment factory in East Delhi, which she quit due to pregnancy which made it difficult for her to continue working on the machine. She shared that, in addition to the health-related aspects, she would feel awkward and 'out of place' to go to work during that period, and thus, decided to leave the job. Her narrative highlights the need to account for the experiences of women at different stages of the life cycle, and the implications it holds for the reproduction of the factory as a highly 'masculine' space. ${ }^{8}$ Women leaving work in factories on account of pregnancy and subsequent childcare responsibilities, is a common pattern that repeats itself in the employment histories of other workers in our study. De Neve (2012) observes in the case of women workers in Tiruppur, that since migrant women have fewer support networks of kith and kin, home-based work offers an incomeearning opportunity alongside their primary responsibilities of childcare. As almost all the women in our study belong to nuclear households in the city, with the extended family residing back in the village, we may suggest that lack of support of kin networks may be a factor as to why some women choose to undertake home-based work. This is also expressed in the backdrop of concerns over safety and security of children, especially young girls, as women shared that they find it unsafe to leave their kids alone at home. This concern was articulated very powerfully by Neena Jha, who lives in Ghazipur village and chooses to work in an electrical wiring workshop in the vicinity that allows her the flexibility to run back and forth between the home and the workshop to check on her kids during the day. She argues:

Men can undertake any kind of work anywhere, but women cannot. A woman will work only if she gets a respectable job, even then, while she will fix her gaze at work, her soul remains at home. She is constantly worried about her children to whom she gave birth, and ponders whether they are safe and sound. What has the father got to worry about? Tomorrow, if I die and my children become vagabond, he will find someone else [some other woman]. This is true of the world, not just my individual case.

Many home-based workers in our study were also told by their husbands not to work outside in the name of 'family honour' or for reasons related to their safety. As Elson and Pearson (1981: 100) observed, 'the fact that if his wife works in a factory she will be subject to the authority of other men may be a powerful reason for a husband wishing to confine his wife to the home.' Home-based work then, seemed the only option available to women given the strict control over their movement outside the home. Gomti, aged about fifty years, a home-based worker, shares that every time she expressed to her husband, her desire to work outside, her husband dismissed the idea, arguing that he was earning enough to support the family. She said that her husband was fine with any work from 
home, but would never allow her to work outside. Interestingly, Gomti remarks that she works not out of financial need but because she is 'fond of working.' She further shared that a few women from the locality were working in a nearby workshop that manufactured nail-paints, located a few hundred meters away from her house. Seeing other women of the locality working there, Gomti also wanted to work, but was discouraged by both her husband and her son. Presently, she makes small decorative pieces at home after finishing her household work whenever she gets time. In her words:

I will do whatever work I get to do from home. After we finish our household work, there is nothing to do. For how long can a person sit idle? For how long can a person sleep?

Gomti does not earn much from her work and acknowledges that she is underpaid. Somewhere, her decision to undertake home-based work comes across as a means of using her time at home 'meaningfully.' We argue that home-based work allows Gomti, and others in our study to deal with the entrapment within their homes by husbands who think their wives need not work outside the home, if they are able to provide for them. Several accounts of home-based workers in our study emphasised the desire to work, after seeing other women in the neighbourhood undertake similar work. In addition, women also shared how the work enables them to use their time better, instead of sitting at 'idle' at home. As one home-based worker put it, 'ghar baithe-baithe ghabrahat ho jaati hai' ('sitting at home throughout [the day], we feel restless'). While Gomti's husband was fine as long as she was working from home, Geeta and Sapna were strongly discouraged by their husbands, arguing that they should take care of their domestic responsibilities, and that there was no need for them to work, since they (husbands) were capable of providing for their needs. Historically, low pay in home-based and other kinds of informal work has been justified by a dominant social bias that looks at women's earnings as 'supplementary' (Sen, 1999, Nagar et al. 2002). When women tell us about their earnings as upari kamai ('secondary earnings'), we do not take such expressions at their face value and see them as representative of the larger political economy of home-based work in India. In case of married women, the act of downplaying the significance of income from this work can be attributed to the idea of 'hegemonic femininities' (Ray 2000) through which women workers show that their survival is taken care of by the breadwinners in the family, since paid work for women is not a "natural" activity within the institution of marriage (Shaheen 2014). While the women home-based workers do not explicitly acknowledge monetary considerations in taking up this work; a deeper probing shows an enabling role, however small, that the earnings from this work hold for them. Many of them stressed how even though the income that they earned form this work was erratic and fluctuated depending on the work at the factories/ workshops, it allowed them to pay for the everyday small desires of their children, enabling them to fulfil their children's desires of eating out and buying small gifts, and not have to worry about overshooting the household budget, or being humiliated or ridiculed by their husbands for doing so. When we asked them whether they plan to spend anything on themselves, Gomti remarked that she had purchased silver jewellery, and Sapna shared with us her plans to save up to buy gold for herself. These micro-stories reflect, as Kabeer (2000:332) notes, 'a powerful desire to have some degree of economic agency, to 'count' for somebody within the family.' It is well understood that home-based work is one among the most precarious forms of work organisation that consciously plays into the gendered vulnerabilities of women and relegates them back into the space of the home, in turn creating a cheap, docile and flexible pool of workers (Raju 2013). Estimates for 2004-05 suggest that about 
$45 \%$ of women workers in the unorganised sector in urban areas work from their own homes (NCEUS 2007: 80). Despite the precarious and vulnerable nature of the work, narratives like the above are noteworthy, for they reveal how by undertaking work within the sphere of one's own home, in a situation wherein other forms of work such as factory work are seen as undesirable and lacking respect, women legitimise their participation in the labour market, and through that, negotiate the gender relations in their own homes.

\section{Redefining spaces and (re)negotiating gender roles}

If the narratives of home-based workers reveal how women construct the site of their own home as a space to contest gendered identities, the narrative of Kusum who works in the packing department of a steel factory in the Wazirpur industrial area, moves away from the centrality of home. Like some home-based workers, Kusum emphasises that she works not out of financial distress, but because she likes to work. She wants to work since she believes there is nothing to do at home after a point of time. She notes also the sense of financial independence she obtains through wage work. Yet, for her, the factory holds out as a space, where in the midst of other working women, she does not realise when time has passed away, and one where the roti (bread) tastes good.

It is nice and cold inside the factory. There's cold water to drink. So, it is nice to work there. While at work, the food also tastes good-here, in eating alone at home, it is not as tasty (Kaam karte karte khana khane main swaad bhi aata hai-yaha ghar mein akele khane mein woh swaad nahi aata). There, I get to talk with the other women who also work, and while working together, one does not realise the time passing by. In the home, we work, and then we just sleep after eating-it feels useless. At the factory, while working, when we eat our roti (bread), then it tastes good, but here, sitting at home, we do not get that taste.

Kusum's narrative highlights the symbolic, material, and social significance of a 'formal' workplace in relation to home. While we get a sense that she is content with her work, we also want to point out that her content emanates from a place of deprivation and exclusion that she faces as an urban poor and as a migrant woman-the chilled water at the workplace assuming a particular significance since she lacks it at home. Further, what is compelling in the narrative is the appropriation of the roti as a symbol of her agency. By arguing that the roti (which she herself has cooked) tastes good only in the space of the factory, along with other working women, and that she does not enjoy eating alone at home, Kusum tries to contest the primacy accorded to the home, while appropriating the roti as a symbol. For Kusum, then, we might say, the factory becomes a site for negotiating her own entrapment in the space of the home, through appealing to symbols that at the same time reinforce the gender division of labour.'Women value the shop floor as a site for social interaction and for the production of sociality itself, which is facilitated by regimes that allow them spatial mobility and communication at work,' observes De Neve (2012:13). We suggest that spatial mobility enables Kusum to appropriate the mundane objects and acts differently, thereby allowing her to claim a different work identity for herself. In addition to contesting the legitimacy of home, her narrative reflects the social value attached to the workspace-the roti as such takes on a different meaning on account of the camaraderie among the women in her factory.

Such relationships also extend well beyond the workplace, and often come to define a certain way of life for women in the settlements where they reside, which many of them 
find liberating in relation to the norms back in their native villages. Especially, narratives of socialisation in the locality abound in the accounts of the home-based workers in our study, who often value the period of time when they step out of their homes in small groups to collect materials from the nearby workshops. On our visits to the settlements, many workers could also be found sitting together in small groups on cots and floor mats, chatting as they pieced the materials together. As one of the home-based workers eloquently put it:

In village, one is bound [to stay inside home] because of extended familial relationships. Because of these familial relationships, you cannot even walk on street [by yourself] as people will see you [and gossip]. Here, it feels free as there is nobody to see me and I can work and live the way I feel like [...] nobody from my husband's family lives here.

The above narrative, in addition to informing us about an individual experience, gives us insights into the wider social relations in migrant workers' settlements where gender relations are renegotiated. Thus, stepping out of home, even if for a limited period of time to collect materials; sitting around with other women in the locality, chatting and putting materials together; are experiences that are located by us in places wherein such activities have a certain kind of legitimacy. This is not to say, however, that the norms and social relations that restrict women's movement(s) in the village, are completely absent from the city. The networks through which workers move to cities and find jobs, are also the sources which produce places-spaces that come into meaning through certain specifics like language, festivals, values and culture-where migrant workers live in a particular manner, often reproducing the village. This aspect starkly emerges when one looks at the widespread celebration of Chhat Puja by the working class in the city, a traditional festival from rural Bihar and Uttar Pradesh that offers reverence to the sun god. ${ }^{9}$ Further, in a discussion with a group of women home-based workers in Ghazipur village, one of them remarked "It [the neighbourhood] feels just like our village. All the people living nearby are from our village. They are all from Bihar, and speak our native language". While the tendency to live close to each other, on the one hand provides a sense of togetherness and strength; on the other hand, it replicates the relations of power and control which govern women's behaviour. The fact that one's co-villagers and relatives live in the same locality often impacts the choices of work and leisure one makes. This draws our attention to the fact that a prospect of the city enabling migrant women to 'rewrite gender relations' (Kaur 2006) in relation to their villages is not necessarily the case. Scholarship in the context of female-led migration (Kaur 2006, Neetha 2004) has underscored the empowering and enabling potential of migration. However, in our study, where most women migrated with their husbands, we encounter a slightly more complex picture. The degree of freedom the city offers to women is determined by whether the locality is inhabited by their husband's kin members and covillagers. It can be broadly interpreted from the accounts in our study that it is relatively easier for women to take up paid work in the localities which are more mixed in terms of residents' regional backgrounds. This is in consonance with studies which argue that the localities that tend to be more or less homogeneous often turn into places where the restrictions on women's mobility are stricter (Phadke et al. 2011, Khan 2007). We argue that whether workers choose home-based work, factory work, or domestic work is further determined by the spatial mobility options they have, which in turn shape their relationships with other women in the settlements. Home-based work, in particular, then becomes a means of not just overcoming entrapment and loneliness at home, but also of 
building new social relationships within the overlapping geographies of work and residence.

\section{Conclusion}

By looking at the role of worksites in shaping women's labour market decisions, this paper has attempted to understand women's decisions to enter particular kinds of paid work. A wide range of literature on feminist geography shows how women are confined in the space of home, which hinders their mobility outside. Notions of family honour and respect contribute deeply to shaping their choices of avoiding conventional workplaces like factories, and working from home instead, further reinforcing their status as secondary earners. Yet, as the narratives of home-based workers show, while movement outside the home is restricted, work from home holds meaning and value beyond its economic significance. We suggest that women's decisions to choose one's own home or other's home as a site of work over the factory reflects their negotiations against familial codes of respect and honour. At the same time, as narratives of some of the home-based workers show, in making these choices, women emphasise the element of power and control they gain over their work, however limited. In contrast, factory workers underscore the significance of spatial mobility as a means to overcome the constraints inherent in the home as a site of work as well as to negotiate gender relations in the household.

While the narratives in this paper are situated within a broader framework of informal, precarious and low-paid wage employment, they show that women are not passive recipients of these phenomena. The three forms of work in the informal sector, as discussed in this paper, are characterised by a combination of gains and constraints for women. The decision to take up a particular kind of work, or move from one form to another is, essentially about navigating those gains in relation to the vulnerabilities and constraints, which we argue are spatially embedded in the worksites.

\section{BIBLIOGRAPHY}

Abraham, Janaki (2010) 'Veiling and the Production of Gender and Space in a Town in North India: A Critique of the Public/Private Dichotomy', Indian Journal of Gender Studies, 17(2), pp. 191222.

Abu-Lughod, Leila (2002) 'Do Muslim Women Really Need Saving? Anthropological Reflections on Cultural Relativism and Its Others', American Anthropologist, 104(3), pp. 783-90.

Acker, Joan (1990) 'Hierarchies, Jobs, Bodies: A Theory of Gendered Organizations', Gender and Society, 4(2), pp. 139-58.

Ahearn, Laura M. (2012) 'Language and Agency', Annual Review of Anthropology, 30, pp.109-37. 
Anand, Anvita; Tiwari, Geetam (2006) 'A Gendered Perspective of the Shelter-TransportLivelihood Link: The Case of Poor Women in Delhi', Transport Reviews, 26(1), pp.63-80.

Arizpe, Lourdes; Aranda, Josefina (1986) 'Women Workers in the Strawberry Agribusiness in Mexico', in Eleanor Leacok, \& Helen I. Safa (eds.), Women's work: Development and the Division of Labour by Gender, New York: Bergin \& Garvey Publishers, pp. 174-93

Baydar, Gulsum (2012) 'Sexualised productions of space', Gender, Place \& Culture, 6(19), pp. 37-41. Bondi, Liz; Davidson, Joyce (2005) ‘Situating Gender', in Lise Nelson \& Joni Seager (eds.), A Companion to Feminist Geography, Carlton: Blackwell, pp. 15-31.

Chakrabarty, Dipesh (1992) 'Of Garbage, Modernity and Citizen's Gaze', Economic and Political Weekly, 27(10-11), pp. 541-47.

Coelho, Karen; Venkat, T.; Chandrika, R. (2013) 'Housing, Homes and Domestic Work: A Study of Paid Domestic Workers from a Resettlement Colony in Chennai', Economic and Political Weekly, 48 (43), pp. 39-46.

De Neve, Geert (2012) 'Fordism, Flexible Specialisation and CSR: How Indian Garment Workers Critique Neoliberal Labour Regimes’, Ethnography, pp. 1-24.

Devika, J.; Nisha, P.R.; Rajasree, A.K. (2011) “A Tactful Union’: Domestic Workers' Unionism, Politics', Indian Journal of Gender Studies, 18(2), pp.185-215.

Elson, Diane; Pearson, Ruth (1981) “Nimble Fingers Make Cheap Workers': An Analysis of Women's Employment in Third World Export Manufacturing', Feminist Review, 7, pp. 87-107.

Fernandez-Kelly, Patricia; Wolf, Diane (2015) 'A Dialogue on Globalization', Globalization and Gender, 26(4), pp. 1243-49.

Ghosh, Jayati (2004) 'Globalization, Export-oriented Employment for Women and Social Policy: A Case Study of India', in S. Razavi, R. Pearson, \& C. Danloy (eds.), Globalization, Export-oriented Employment and Social Policy: Gendered Connections, New York: Palgrave Macmillan, pp. 91-125. Gottffried, Heidi (2013) Gender, Work and Economy: Unpacking the Global Economy, Cambridge: Polity Press.

Hanson, Susan; Pratt, Geraldine (1995) Gender, Work, and Space, London: Routledge.

Harriss-White, Barbara; Prosperi, Valentina (2014) 'The Micro Political Economy of Gains by Unorganised Workers in India', Economic and Political Weekly, 49(9), pp. 39-43.

Herod, Andrew (2003) ‘Workers, Space and Labour Geography', International Labor and WorkingClass History, 64, pp. 112-38.

Kabeer, Naila (2000) The Power to Choose: Bangladeshi Women and Labour Market Decisions in Dhaka and London, London: Verso.

Kaur, Ravinder (2006) 'Migrating for Work: Rewriting Gender Relations', in Sadhna Arya \& Anupama Roy (eds.), Poverty, Gender and Migration, New Delhi: Sage Publications, pp. 193-213.

Kaviraj, Sudipta (1997) 'Filth and the Public Sphere: Concepts and Practices about Space in Calcutta’, Public Culture, 10 (1), pp. 83-113.

Khan, Sameera (2007) 'Negotiating the Mohalla: Exclusion, Identity and Muslim Women in Mumbai', Economic and Political Weekly, 48 (36), pp. 1527-33.

Lefebvre, Henri; Levich, Christine (1987) ‘The Everyday and Everydayness’, Yale French Studies, 73, pp. 7-11. 
Low, Martina (2006) 'The Social Construction of Space and Gender', European Journal of Women's Studies, 13(2), pp.119-33.

Mahmood, Saba (2001) 'Feminist Theory, Embodiment, and the Docile Agent: Some Reflections on the Egyptian Islamic Revival', Cultural Anthropology, 16(2), pp.202-36.

Massey, Doreen (1994) Space, Place and Gender, Minneapolis: University of Minnesota Press.

Morus, Amanda (2008) 'The Private Home as a Public Workplace: Employing Paid Domestic Labour', Journal of Workplace Rights, 13(4), pp. 377-400.

Nagar, Richa; Lawson, Victoria; Mcdowell, Linda; Hanson, Susan (2002) 'Locating Globalization : Feminist (Re) readings of the Subjects and Spaces of Globalization', Economic Geography, 78(3), pp.257-84.

NCEUS (2007) Report on Conditions of Work and Promotion of Livelihoods in the Unorganised Sector, New Delhi: National Commission for Enterprises in the Unorganised Sector.

Neetha, N. (2004) 'Making of Female Breadwinner: Migration and Social Networking of Women Domestics in Delhi', Economic and Political Weekly, 39(17), pp. 1681-88.

Neetha, N. (2008) ‘Regulating Domestic Work’, Economic \& Political Weekly, 43(37), pp. 26-28.

Neetha N. (2009) 'Contours of Domestic Service: Characteristics, Work Relations and Regulation', Indian Journal of Labour Economics, 52(3), pp. 489-506

Neetha, N.; Palriwala, Rajni (2010) 'The Absence of State Law: Domestic Workers in India', Canadian Journal of Women and the Law, 23(1), pp. 97-119.

Parthasarathy, D (2013) 'Rural, Urban, and Regional: Re-spatializing Capital and Politics in India', in T. Bunnell et al. (eds.), Cleavage, Connection and Conflict in Rural, Urban and Contemporary Asia, ARI - Springer Asia Series 3, DOI 10.1007/978-94-007-5482-9_2.

Phadke, Shilpa; Khan, Sameera; Ranade, Shilpa (2011) Why loiter? Women \& Risk on Mumbai Streets, New Delhi: Penguin Books.

Raghuram, Parwati (2001) 'Caste and Gender in the Organization of Paid Domestic Work in India', Work, Employment \& Society, 15(3), pp. 607-17.

Raju, Saraswati (2013) 'The Material and the Symbolic: Intersectionalities of Home-Based Work in India', Economic and Political Weekly, 48(1), pp. 60-68.

Ranade, Shilpa (2007) 'The Way She Moves: Mapping the Everyday Production of Gender and Space', Economic and Political Weekly, 42(17), pp. 1519-26.

Ray, Raka (2000) 'Masculinity, Femininity and Servitude: Domestic Workers in Calcutta in the Late Twentieth Century', Feminist Studies, 26(3), pp. 691-718.

Richardson, Miles (1982) 'Being-in-the-Market versus Being-in-the-Plaza: Material Culture and the Construction of Social Reality in Spanish America', American Ethnologist, 9(2), pp. 421-36.

Ruwanpura, Kanchana N. (2013) 'Scripted Performances? Local Readings of "Global” Health and Safety Standards (The Apparel Sector in Sri Lanka)', Global Labour Journal, 4(2), 88-108, URL: https://escarpmentpress.org/globallabour/article/view/1133

Sen, Samita (1999) Women and Labour in Late Colonial India: The Bengal Jute Industry, Cambridge: Cambridge University Press.

Shaheen, Anwar (2014) ‘Marriage, Women’s Economic Participation and Patterns of Support in Urban Karachi', in Ravinder Kaur and Rajni Palriwala (eds.), Marrying in South Asia: Shifting Concepts, Changing Practices in a Globalized World, Delhi: Orient Blackswan, pp. 183-207. 
Siddiqi, Dina M. (2003) 'The Sexual Harassment of Industrial Workers: Strategies for Intervention in the Workplace and Beyond', Centre for Policy Dialogue-United Nations Population Fund (CPDUNFPA) Paper 26.

\section{NOTES}

1. The findings of this paper are based on a larger research project on the relationship between migration, industrial work and worker identities in the city of Delhi, housed at the School of Development Studies, Ambedkar University, Delhi; and funded by the Indian Council of Social Science Research, New Delhi and Indira Gandhi Institute of Development Research, Mumbai; with which the authors were associated as researchers. We thank Sumangala Damodaran for her encouragement as the project director to explore the research questions pursued in this paper, and for helpful feedback on an earlier draft. Earlier versions of this paper were presented at the 16th Workshop Young Researchers, Association Jeunes Études Indiennes (AJEI), on Labour, mobility and mobilization, 11-14 February 2014, Centre for Informal sector and Labour Studies, School of Social Sciences, Jawaharlal Nehru University, New Delhi, and at the Centre for Policy Research Discussion Group series, 11 November 2014. We are grateful to Loraine Kennedy for extensive feedback on previous drafts, to participants at the aforementioned workshops for thought provoking questions and comments, and to Saumyajit Bhattacharya, Jesim Pais and Jules Naudet for helpful discussions. We are grateful for the comments of three anonymous reviewers of SAMAJ in fine-tuning the arguments presented. The usual disclaimers apply. We thank all the women workers who participated in this study, and generously opened up about their everyday lives to us. We are also grateful to our colleagues on this project for a stimulating and enriching work environment - Arpit Gaind, Mritunjay Tripathi, Anushka Rose, Vichkshna Bajaj, Shipra, Sukrit Nagpal, Shikha Nehra, Swati M. Krishnan, Antara Rai Chowdhury, Abhishek Sharma, Kriti Barman, Renu Bala, Nikita Khanna, and Jasmeet Khanuja; and to Sangeeta at the School of Development Studies office for her assistance in managing the project.

2. This visit was undertaken specifically to fine-tune findings with regard to the gender dimensions of migration in the city as part of the larger project, which one of us (Eesha Kunduri) conducted with another colleague on the project, Nikita Khanna.

3. Wazirpur industrial area, which was developed during the late $1960 \mathrm{~s}$, is primarily dominated by hot-rolling steel units manufacturing steel utensils and some garment units. The industrial profile of the Patparganj estate, on the other hand, consists of garments, packing, packaging, printing presses, and manufacture of auto-parts, tobacco, and incense sticks. In addition, there are vehicle service centres and call centres operating within the Patparganj estate. The Patparganj Industrial Estate was developed in the 1990s.

4. The ILO Home Work Convention No.177 defines a homeworker as 'a person who carried out work for remuneration in premises of his/her choice, other than the work place of the employer, resulting in a product or service as specified by the employer, irrespective of who provided the equipment, material or inputs used' (cited in NCEUS, 2007). The term, home-based worker, on the other hand is a broader category used to denote both homeworkers as well purely self-employed workers who work out of their homes. In this paper, our use of the terms home-based worker refers to workers working under sub-contracts, and not the self-employed home-based workers. For a detailed discussion, see http://wiego.org/informal-economy/occupational-groups/homebased-workers

5. The National Commission for Enterprises in the Unorganised Sector, in one of its reports, observed that 'the conventional idea of a workplace is the office, factory or an institution. In 2004-05 [...] as little as one-third of the women workers worked in conventionally designated workplaces' (NCEUS 2007: 79). 
6. As Neetha (2009), in her critique of the limitations of official figures to capture the actual extent of feminisation in paid domestic work has observed, certain tasks in the umbrella category of 'domestic work' as captured by the government agencies such as gardening and watchman are more likely to be 'male centred', while others such as cleaning and laundry are conventionally 'female centred.'

7. All names are pseudonyms.

8. Ruwanpura (2013) notes in an ethnographic study of two Sri Lankan garment factories, that pregnant women are taken off as operators of machines, and shifted to being 'helpers' of machines, in the name of worker safety and welfare. Some women seemed to accept this move as best for them, even though it led to a lower pay on account of being 'helpers.' Some, however, requested the factory management that they should be allowed to choose whether they would like to continue as machine operators or switch to being helpers, on account of the financial loss the move entailed. Subsequently, a change in policies was brought out to allow workers choice in this regard. The author observes how the rationalisation of this move as a response to workers' concerns ignores, at one level, other ways to address pregnant women's issues, and at another, reinforces gendered hierarchies and authority at the workplace.

9. In the context of Mumbai, Parthasarathy (2013) talks about how the socio-political and spatial character of the city has undergone a change with the public celebration of certain festivals like the Chhat Puja by migrants from Bihar and Uttar Pradesh.

\section{ABSTRACTS}

This paper explores the spatiality and temporality of women's decisions to navigate particular forms of paid work, through means of a comparative analysis of three different sites and forms of work-at one's own home (as home based workers), someone else's home (in the form of paid domestic work) and conventional workplaces like factories (as shop-floor workers and as cleaners). By contextually situating the varying expressions of choice across the three sites, the paper argues that women's efforts to choose one kind of work arrangement over another are embedded in the power and control that certain spaces of work entail. It further posits that women workers actively seek to reshape and redefine these spaces, through conscious negotiations in everyday practice as well as discourse.

\section{INDEX}

Keywords: spatial embeddeness, gender and work, agency, Delhi, industrial work, domestic work, home-based work

\section{AUTHORS}

SONAL SHARMA

Researcher at the Centre for Policy Research, New Delhi 


\section{EESHA KUNDURI}

Researcher at the Centre for Policy Research, New Delhi 